\title{
Elective neck dissection in early oral squamous cell carcinoma: necessary?
}

\section{Carlos Moreno-García}

Department of Oral and Maxillofacial-Head and Neck Surgery, University Hospital Infanta Cristina, 06080 Badajoz, Spain. Corresponding author: Dr. Carlos Moreno-García, Department of Oral and Maxillofacial-Head and Neck Surgery, University Hospital Infanta Cristina Ctra de Portugal, 06080 Badajoz, Spain. E-mail: carlosmorenogar@gmail.com

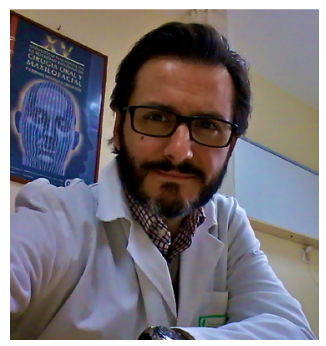

\begin{abstract}
Dr. Carlos Moreno-García, M.D., obtained his Medical Degree at the University of Extremadura School of Medicine in Badajoz, Spain, in 1999. He received in 2003 his Specialty in Family and Community Medicine at the Teaching Unit of the La Paz Health Center in Badajoz, Spain, and his Specialty in Oral and Maxillofacial Surgery at the University Hospital Infanta Cristina, Badajoz, Spain in 2009. He has been consultant at the Department of Oral and Maxillofacial Surgery in University Hospital Infanta Cristina, Badajoz, Spain, since then. Actually, he is University Honorary Collaborator at the University of Extremadura School of Medicine, Badajoz, Spain.
\end{abstract}

ABSTRACT

Aim: The indication of neck dissection in oral squamous cell carcinoma (OSCC) is a problem of risk-benefit evaluation between probability of neck metastases, the problem of complications associated with neck dissection and the prognostic influence of delayed diagnosis of metastasis during follow-up. There is no consensus on the elective treatment of the neck in early oral cancer patients with a clinically N0 (cN0) neck. Methods: The author performed a search of PubMed articles with the words "elective neck dissection vs. observation", "node negative neck" and "early stage oral squamous cell carcinoma". The author selected those articles that studied the early OSCC (T1-T2), and elective neck treatment was compared with clinical observation. Results: Many studies have compared the outcome of elective neck dissection (END) to observation of the neck in early OSCC. The results of them are described. The biologic aggressiveness of oral cavity squamous cell carcinoma, particularly in the early stages, is reflected in its ability to metastasize to regional lymph node chains. Many pretreatment imaging techniques to diminish the incidence of occult metastases haven been studied, and comparative studies have shown ultrasound guided fine needle aspiration cytology (USgFNAC) to be the most accurate. Conclusion: A few non-randomized studies have shown no advantages of END when strict USgFNAC follow-up was employed. Thus, if routine strict follow-up using USgFNAC by a welltrained ultrasonographer cannot be assured, END is the safest strategy.

Key words:

Early stage; oral squamous cell carcinoma; negative lymph necknode; elective neck dissection versus observation

\section{INTRODUCTION}

Management of the clinically negative neck in patients with T1-T2 oral cancer remains controversial [Figure 1]. The single most important tumor-related prognostic factor in patients

\begin{tabular}{|l|l|}
\hline \multicolumn{2}{|c|}{ Access this article online } \\
\hline Quick Response Code: & Website: \\
\hline & http://www.parjournal.net \\
\cline { 2 - 3 } & \\
\hline
\end{tabular}

with head and neck squamous cell cancer is the status of the cervical lymph node. ${ }^{[1-5]}$ Patients with lymph node metastases require treatment of the neck. When the neck

This is an open access article distributed under the terms of the Creative Commons Attribution-NonCommercial-ShareAlike 3.0 License, which allows others to remix, tweak and build upon the work non-commercially, as long as the author is credited and the new creations are licensed under the identical terms.

For reprints contact: service@oaepublish.com

How to cite this article: Moreno-García C. Elective neck dissection in early oral squamous cell carcinoma: necessary? Plast Aesthet Res 2016;3:167-74.

Received: 29-03-2016; Accepted: 17-05-2016 


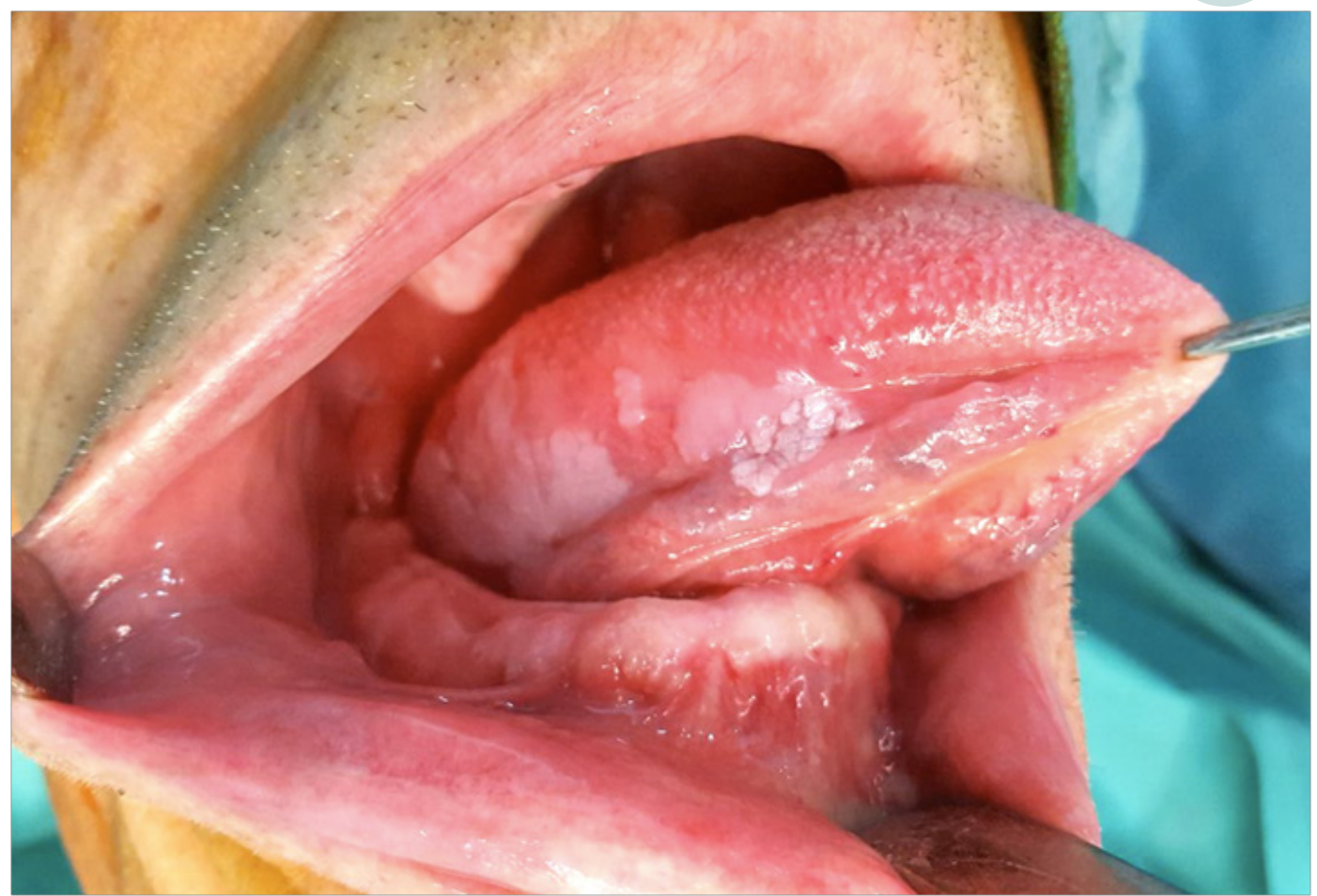

Figure 1: Clinical Stage I (T1N0M0) squamous cell carcinoma of the tongue

needs to be entered for excision of the primary tumor or reconstruction of the surgical defect, a neck dissection needs to be performed. ${ }^{[6-10]}$ Currently, management of the clinically negative ( $\mathrm{CN} 0$ ) neck in patients whose tumor can be resected transorally remains controversial. ${ }^{[1-1-15]}$ In general an elective neck dissection (END) is justified if the estimated risk of occult lymph node metastases exceeds $15-20 \%{ }^{[16-20]}$

Although screening of clinically N0 neck by ultrasound, computed tomography (CT) magnetic resonance imaging (MRI), or positron emission tomography (PET) can help to detect some of these non-palpable nodal metastases, the recurrence rate in the observed N0 neck is $23.7-42 \% .{ }^{21-25]}$

The indication of neck dissection in oral squamous cell carcinoma (OSCC) is a problem of risk-benefit evaluation between probability of neck metastases, the problem of complications associated with neck dissection and the prognostic influence of delayed diagnosis of metastasis during follow-up. ${ }^{[2-30]}$ Although END results in early treatment of occult lymph node metastases, the vast majority of these neck dissections harbors no metastases and was unnecessary. ${ }^{[3-35]}$ Moreover, these patients are subjected to morbidity such as shoulder morbidity, pain and sensibility disorders, which may have major impact on health-related quality of life. ${ }^{[36-40]}$ Furthermore, neck dissection may remove a barrier to cancer spread in case of local recurrence or second primary tumor. $^{[41-45]}$ There is no consensus on the elective treatment of the neck in early oral cancer patients with a cN0 neck. ${ }^{\mid 46-50]}$

\section{METHODS}

We performed a search of PubMed articles with the words "elective neck dissection versus observation", "node negative neck" and "early stage oral squamous cell carcinoma": ("elective surgical procedures" [MeSH Terms] OR ("elective"[All Fields] AND "surgical" [All Fields] AND "procedures" [All Fields]) OR "elective surgical procedures" [All Fields]
OR "elective" [All Fields]) AND ("neck dissection" [MeSH Terms] OR ("neck" [All Fields] AND "dissection" [All Fields]) OR "neck dissection" [All Fields]) AND versus [All Fields] AND ("observation" [MeSH Terms] OR "observation" [All Fields]). Node [All Fields] AND negative [All Fields] AND ("neck" [MeSH Terms] OR "neck" [All Fields]). Early [All Fields] AND stage [All Fields] AND ("mouth" [MeSH Terms] OR "mouth" [All Fields] OR "oral" [All Fields]) AND ("carcinoma, squamous cell" [MeSH Terms] OR ("carcinoma" [All Fields] AND "squamous" [All Fields] AND "cell" [All Fields]) OR "squamous cell carcinoma" [All Fields] OR ("squamous" [All Fields] AND "cell" [All Fields] AND "carcinoma" [All Fields])).

We selected those articles that studied the early oral squamous cell carcinoma (T1-T2), and elective neck treatment was compared with clinical observation. We only included studies published in the English language and those dealing with "squamous cell carcinoma of the oral cavity".

The following technical biliographic exclusion criteria were applied: (1) case reports; (2) technical reports; (3) animal or in vitro studies; (4) uncontrolled clinical studies; and (5) publications in which the same data were published by the same group of researchers.

\section{RESULTS}

Many studies ${ }^{[4-6,10,15]}$ have compared the outcome of END to observation of the neck. In the prospective study of O'Brien et al. ${ }^{[4]}$ management of the cN0 neck in T1-T4 oral cancer patients was based on clinical criteria such as $T$-classification and tumor site, which makes comparison of survival between treatment options difficult. Two studies showed statistical significant difference in disease specific survival or overall survival between END and observation. ${ }^{[13,15]}$ However, Huang et al ${ }^{[13]}$ did not describe surveillance of the neck in the observation arm and if absent or merely clinical, this may have influenced 
survival. The group of La Princesa University Hospital[51] (Madrid, Spain) analyzed only END patients who were pN0, which obviously resulted in better overall survival in END patients. Three studies reported a significantly better disease-free survival in the END arm. ${ }^{[6,13,15]}$

Fasunla et al..$^{[52]}$ systematically reviewed the available literature and performed a meta-analysis on the existing randomized controlled clinical trials which compared END with observation (and therapeutic neck dissection only when lymph node metastasis were detected) in early OSCC patients. Only four randomized clinical trials with a total of 283 patients were eligible for inclusion in this meta-analysis. Although the data used in that meta-analysis were from different parts of the world, between study heterogeneity of the relative risk of disease specific death in the trials were tested and no statistically significant difference were found. This meta-analysis showed that END significantly reduced the risk of disease specific death: fixedeffects model $\mathrm{RR}=0.57$ [95\% confidence interval $(\mathrm{CI}) 0.36$ $0.89 ; P=0.014]$ and random-effects model $R R=0.59(0.37$ $0.96 ; P=0.034) \cdot{ }^{[52]}$

D’Cruz and Dandekar ${ }^{[53]}$ from Tata Memorial Center (Mumbai, India) performed a critical appraisal of this meta-analysis which revealed "some caveats that need careful consideration before the findings can be accepted". They pointed out the poor follow-up in one of the included studies that resulted in a large number of patients with advanced neck recurrences and low salvage rates. Finally, they emphasized the need for meticulous follow-up patients on the observation arm. ${ }^{[53]}$ The same group analyzed their series of 359 patients with early oral cancer, found no difference in disease specific survival between END and observation and elaborated the need for a large randomized controlled clinical trial (RCT). ${ }^{[15]}$ The Head and Neck Disease Management group of Tata Memorial Centre performed such a trial, enrolled 596 patients and reported the results of the first 500 patients. The conclusion was that among patients with early stage OSCC, END results in higher rates of overall and disease free survival than observation with therapeutic neck dissection in patients in whom lymph node metastases are detected during follow-up. ${ }^{[54]}$

The group of the Tata Memorial Centre had chosen overall survival as primary endpoint and disease free survival as secondary endpoint for their RCT. END resulted in an improved 3 -year overall survival rate $(80 \%$; $95 \% \mathrm{CI} 74-86)$ as compared with observation and therapeutic neck dissection (68\%; 95\% CI 61-74): hazard ratio of death $0.64(95 \% \mathrm{Cl} 0.45-0.92 ; P=0.01)$. Patients in the END group had a higher disease free survival than those in the observation group $(79 \% v s .46 \%, P<0.001) \cdot{ }^{[54]}$ It is not surprising that END improves the regional control rate because development of lymph node metastases during observation of the neck should be taken into account as an inevitable consequence of the adopted strategy. Therefore, this disease free survival is a useful outcome measure of diagnostic work-up but not a reliable outcome measure in comparing END and observation of the neck.

Ganly et $a l .{ }^{[55]}$ reported on a series on 216 cT1-T2N0 patients treated with or without END and found a 5-year disease specific, overall and disease free survival of $86 \%, 79 \%$ and $70 \%$, respectively. Disease specific survival is probably the most clinically meaningful endpoint for measuring an eventual benefit of END, but unfortunately is not reported in the RCT. As mentioned above, in the meta-analysis of Fasunla et al. ${ }^{[52]}$ END significantly reduces the risk of disease specific deaths.

Flach et $a l^{[1]}$ presents a survival analysis of a large series of patients with T1-T2 cancer of the mobile tongue or floor of mouth with a wait and scan follow-up policy of the neck with regular ultrasound guided fine needle aspiration cytology (USgFNAC). The 5-year disease specific survival (DSS) and overall survival (OS) of "wait and scan" policy (W\&S) patients were $94.2 \%$ and $81.6 \%$, respectively, and these rates were comparable to those of END patients. The most important finding is that in W\&S patients with delayed metastases the 5-year DSS and OS were similar to END patients with proven metastases in the neck dissection specimen: $80.0 \%$ and $62.8 \%$ to $81.3 \%$ and $64.2 \%$, respectively. In order to justify an observation policy, survival rates of patients with delayed metastases in a $W \& S$ policy should not be worse than rates of END patients with nodal metastases in the neck dissection specimen. In the above mentioned series the patients who developed delayed metastases (27.8\%) did not have worse survival rates (DSS $80.0 \%$, OS 62.8\%) as compared to END patients with nodal metastases in the neck dissection specimen (DSS $81.3 \%$, OS 64.2\%), also when corrected for confounding factors. Moreover, with regard to the total study groups after correction for confounding no significant difference in survival between W\&S and END patients was found and survival rates were comparable to the reported rates in literature. ${ }^{[4-6]}$ Out of the W\&S patients, $72.2 \%$ did not develop lymph node metastases during follow-up, meaning that they were saved from END with good survival rates (DSS 99.4\%, OS 89.1\%). Although, DSS in the W\&S group was significantly different between pT1 and pT2 tumors, pT2 tumors still had a 5-year DSS of $88.6 \%$, which resembles the survival rates of END patients.

Tsang et al. ${ }^{[56]}$ stated that "wait and scan" would not be effective in pT2 tumors, but that conclusion was based on a 5-year DSS of $46 \%$ for pT 2 tumors. These authors assumed that the delayed lymph node metastases were missed by preoperative USgFNAC. In a "wait and scan" policy, the diagnostic method should be highly sensitive. This is dependent on the cut off level for aspiration and of the expertise of the radiologist. ${ }^{[57-59]}$ Almost all patients with delayed metastases underwent a modified radical neck dissection and $90.6 \%$ needed adjuvant radiotherapy. Since they also found metastases in level IV, they would recommend selective neck dissection of level I-IV in case of delayed lymph node metastases, although Wensing et al. ${ }^{[60]}$ suggested selective neck dissection of level I-III.

Borgemeester et al. ${ }^{[57]}$ compared the overall survival in head and neck squamous cell carcinoma patients with a clinically NO neck who underwent END or close observation using regular USgFNAC during follow-up. Survival in the OSCC patients of the close observation group was not different from the END group: $90 \%$ and $81 \%$ after 3 years and $79 \%$ and $75 \%$ after 5 years, respectively. Nieuwenhuis et al. ${ }^{[61]}$ showed that by using USgFNAC pretreatment and during follow-up 79\% of the delayed metastases could be salvaged resulting in a regional control rate of $88 \%$.

Yuen et al. ${ }^{[14]}$ performed a prospective multicenter randomized trial in 71 T1-T2 oral cancer patients with cN0 necks 
evaluated by USgFNAC and the patients were stratified for T-staging classification. Observation of the neck consisted of ultrasonographic examination every 3 months during the first 3-year follow-up, which strongly resembles our wait and scan follow-up policy. Although the sample size was limited, this study had the preferable study design to compare the outcome of elective neck treatment with observation. The reported 5-year disease-specific survival rates were not significantly different (observation arm 87\%, END arm 89\%). ${ }^{[14]}$

In the study of Feng et al. ${ }^{[16]}$ total regional recurrence rate of the untreated N0 neck was found to be $19.2 \%$ for stage T1 $(8 / 48$, $16.7 \%$ ) and stage T2 $(6 / 25,24.0 \%)$, respectively. $92.9 \%$ of them occurred in the early postoperative period (within 2 years). Of these regional recurrences, only $41.7 \%$ patients were successful salvaged due to advanced neck disease. In their department, observation policy for dinically N0 neck was more common in patients with the stage T1 tumours, so that the T1/T2 ratio for the randomized controlled study was unbalanced (T1/T2 ratio in "END vs. observation": 0.6 vs. 1.9). Although the patients from the observation group had a higher proportion of stage $\mathrm{T} 1$, They found that the patients from END group exhibited significantly better DSS rates than those from observation group. They further analysed the prognosis of subgroups (T1/T2) in each group, the results showed that the patients from the END group with stage T2 tumours had a higher survival rate than those from the observation group. ${ }^{[16]}$

Weiss et al..$^{[3]}$ suggested that END is necessary if the incidence of occult metastasis is greater than $20 \%$. The proponents of wait and watch policy argue that $80 \%$ of patients with N0 neck would be over treated, and subjected to additional morbidity and costs. Though this argument may apply to most oral cavity tumors, the cancer of the tongue must be viewed as a separate entity. The incidence of nodal metastasis is higher for early cancer of the tongue when compared with other sites of the oral cavity ${ }^{[62,63]}$ D'Cruz et al. ${ }^{[15]}$ found the incidence of nodal metastasis to be $37.5 \%$ in $\mathrm{T} 1$ lesions and $62.5 \%$ in $\mathrm{T} 2$ lesions of the oral tongue. Andersen et al. ${ }^{[64]}$ studied the results of neck failure following observation of N0 necks. They found that $60 \%$ of patients had N2 disease and $49 \%$ had extracapsular spread (ECS). Either or both these adverse prognostic factors were present at the time of surgery in $77 \%$ of patients. ${ }^{[22,62-64]}$

Four RCTs have been performed to compare END with wait and watch policy. Two of the trials were conducted purely on early oral tongue cancers. Fakih et al. ${ }^{[65]}$ in a series on T1 and T2 lesions, compared END with observation. They found that there was no survival difference between the two groups. They found that a tumor depth of more than $4 \mathrm{~mm}$ was associated with higher rates of involved nodes and suggested that these set of patients may benefit from END. A more recent RCT from Hong Kong compared END versus observation for T1 and T2 lesions of the oral tongue. The authors had a robust followup protocol of clinical and ultrasonographic examination of the neck to detect recurrences. They were able to salvage all neck recurrences in the observational arm and thus found no survival differences between the two arms. ${ }^{[14]}$ All the above RCTs had small numbers and consisted of methodology flaws making their conclusions difficult to inculcate into clinical practice.
Vijayakumar et al. ${ }^{[22]}$ found that about $50 \%$ of patients with tongue tumor depth more than $4 \mathrm{~mm}$ had grade III and IV tumors. The incidence of occult metastasis was $62.2 \%$, which is significantly higher than for other subsites of the oral cavity. Thirty eight $(33.9 \%)$ patients with occult metastasis had ECS, which is a poor prognostic feature. Another poor prognostic indicator they detected was multiple levels of nodal involvement in 79 (70.5\%) patients. As expected most of the lymph nodes were localized to levels I, II and III. But level IV was involved in 23 patients. ${ }^{[22]}$

In the study of Huang et al. ${ }^{[13]}$ neck recurrence rate in the OBS group (28.6\%) was significantly higher compared with that observed in the END group $(12.7 \%, P=5.004)$. Although contralateral regional metastases have been described in some series of patients with early stage tumors of the oral cavity, ${ }^{[26,66]}$ their data show that neck recurrence is mainly ipsilateral in patients treated with glossectomy alone. Among patients treated with END, $12.7 \%$ developed a regional recurrence. Contralateral level I lymph nodes were the most frequent site of regional recurrence. This finding was in line with previous data. ${ }^{[66]}$ It is posited that this phenomenon may be due to an afferent communicating pathway that drains from the floor of the mouth into the contralateral lymph nodes. ${ }^{[67]}$ This may also occur silently before surgery. The second most common site of regional recurrence was ipsilateral level I nodes. In their study, the 5-year cervical control rates was much better for patients treated by END compared with OBS. In addition, the 5-year OS in the END group was superior compared with patients who had a subsequent therapeutic neck dissection. These data are in line with previous studies in early-stage tongue cancer. ${ }^{[65]}$ It is thus posited that END might improve both neck control and OS. Indeed, application of this technique might improve the chance of clearance of micrometastasis that cannot be detected by histology or imaging. However, their data provide evidence that, in the group of patients treated by END, the incidence of skip metastasis to level IV in the absence of level I/II lesions is as low as $2.7 \%$ ( 1 case out of 37 patients). In the OBS group, the skip metastasis rate was $5.4 \%$ ( 3 of 56 ) in patients with regional recurrence who received salvage neck dissection. In their report the skip metastatic rate was lower compared with that reported in previous studies. ${ }^{[68-71]}$ However, in their study all patients were staged with the use of CT/MR imaging. In the light of our data, routine dissection of level IV lymph node alongside supraomohyoid neck dissection can provide little benefit to patients with early-stage tongue cancer. It is concluded that level IV nodes should not be routinely included in the neck dissection for patients with negative neck as assessed by CT/MRI scans.

In the study of Dias et al. ${ }^{[6]}$ analyzing the two groups of patients (resection of the primary tumor alone-RA and resection of the primary tumor "plus" elective neck disection-XR+END) according to the incidence of regional recurrence, they found a $24 \%$ incidence in the RA group compared with a $4 \%$ incidence in the R+END group. The $20 \%$ difference between the two groups was statistically significant $(P=0.03)$. Differences between disease-free survival of $97 \%$ for the R+END group and of $74 \%$ for the RA group were also statistically significant $(P=$ 0.05). These findings confirm the results of Kligerman et al. ${ }^{[34]}$ in 


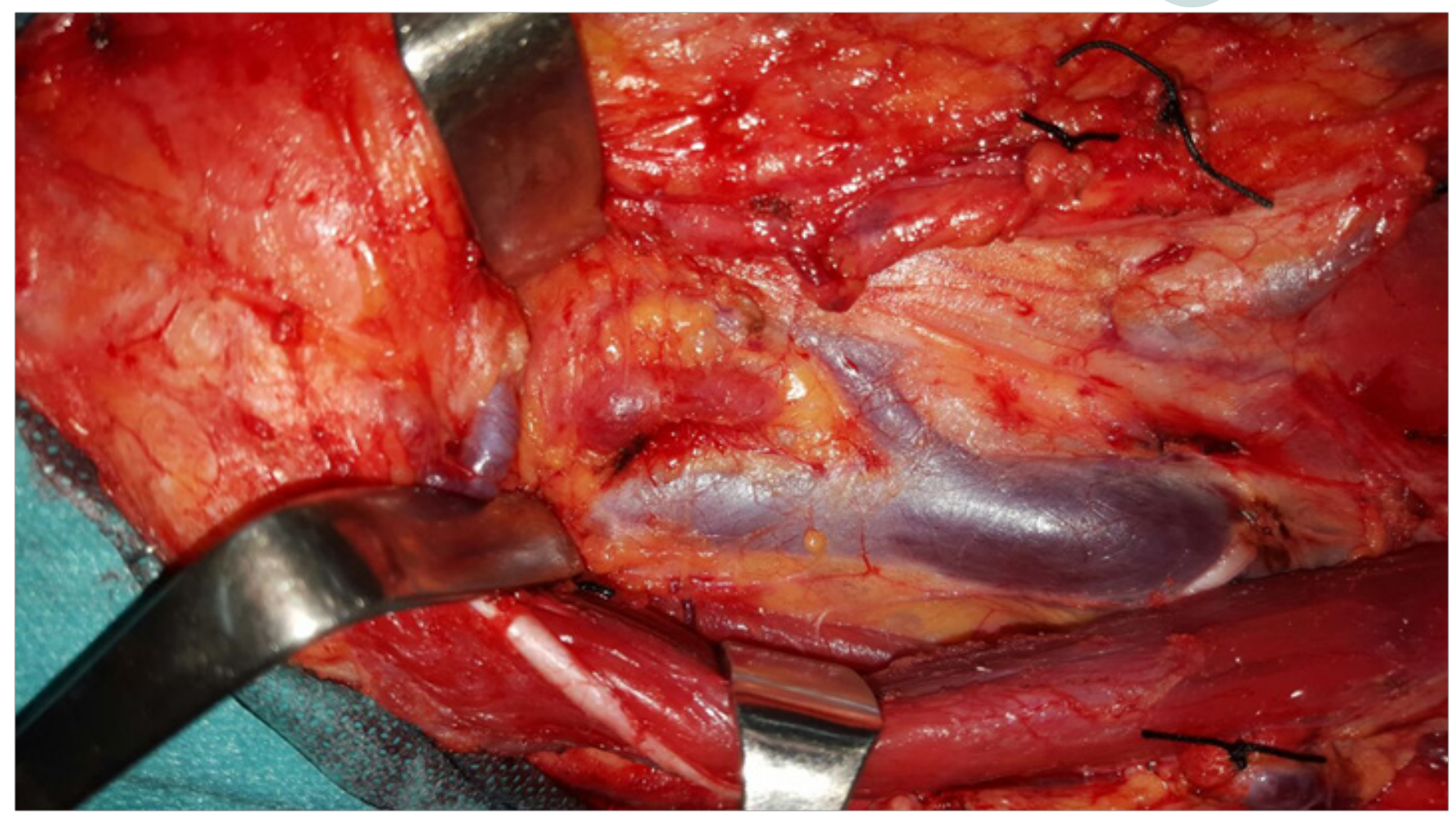

Figure 2: Right selective supraomohyoid neck dissection. Note the appearance of a 1-cm node in the jugulodigastric region (level II) intraoperatively, which was evident neither by palpation nor in the preoperative computed tomography scan. This otherwise not son uncommon situation may justify the performance of elective neck dissection even in T1 squamous cell carcinoma of the oral cavity and oropharynx

their comparative analysis of the outcome in patients treated with END versus observation in early oral cancers.

Most locoregional recurrences in oral cancer patients occur during the early postoperative follow-up period. ${ }^{[23,24,34,38]}$ Analyzing the patterns of regional recurrence in untreated N0 neck patients, they found involvement of multiple nodes of levels I to III, involvement of levels IV and V (2 cases), and involvement of bilateral lymph node metastases (2 cases). These observations clearly confirm the more aggressive behavior of the oral cancer when delayed cervical metastases have become clinically apparent. ${ }^{[26-30]}$

Regional recurrence was the most important cause of failure after surgical treatment in their groups of patients. END, when used, reduced the initial regional recurrence rate and improved the disease-free survival time of patients. The overall $24.5 \%$ incidence of neck metastases allied with the poor rate of salvage in the case of regional recurrence (28.5\%) found in this study strongly suggest the need for elective treatment of the neck in stage I squamous cell carcinoma of the tongue and floor of the mouth. ${ }^{[6]}$

\section{DISCUSSION}

Cervical node metastasis in head and neck cancer is a poor prognostic feature and decreases the survival by $50 \%$. It is obvious that patients with clinically involved nodes require treatment of the neck. However, controversy exists in the management of patients with early cancers and N0 neck. ${ }^{[22,23]}$

The biologic aggressiveness of oral cavity squamous cell carcinoma, particularly in the early stages, is reflected in its ability to metastasize to regional lymph node chains. Because of the rich lymphatic network of the tongue and floor of the mouth (FOM), the risk of development of lymph node metastases in these particular sites varies between $6 \%$ and $46 \%$, even in the early stages. ${ }^{[6,29-33]}$ This metastatic disease is almost always subclinical or occult at the time of the diagnosis and treatment of early tongue and FOM cancers, thereby contributing to the controversy regarding elective treatment of the neck.

END for N0 neck has been increasingly performed for early oral carcinomas. ${ }^{[23,26,33-35]}$ The main reason for this aggressive therapeutic approach is the high index of occult ${ }^{[33,34,36]}$ metastases in association with poor salvage rates for recurrences at the neck.

Although palpation is the most practical means of staging the neck, it has a false-negative rate of about $40 \%{ }^{[38,39]}$ The use of CT may reduce the false negative rate of the staging to $22.7 \%$. ${ }^{[38]}$ The use of MRI or PET scans can further improve detection rates for neck nodal metastases. A high incidence of neck recurrence has been reported in patients with T1-T2 cancer of the oral tongue treated by primary tumor excisions alone..$^{[40,41]}$ Specifically, cervical lymph node metastases developed subsequently in $38 \%$ to $43 \%$ of such patients. ${ }^{[41-43]}$

Management of the clinically negative neck in patients with T1-T2 oral cancer remains controversial. Although END can result in early treatment of occult lymph node metastases, the vast majority of these neck dissections turn out to be unnecessary. Moreover, these patients are subjected to morbidity such as shoulder morbidity, pain and sensibility disorders, ${ }^{[4,45]}$ which may have major impact on health-related quality of life. ${ }^{[46,47]}$ Furthermore, elective neck treatment may remove or destroy a barrier to cancer spread in case of local recurrence or second primary tumor which occur 


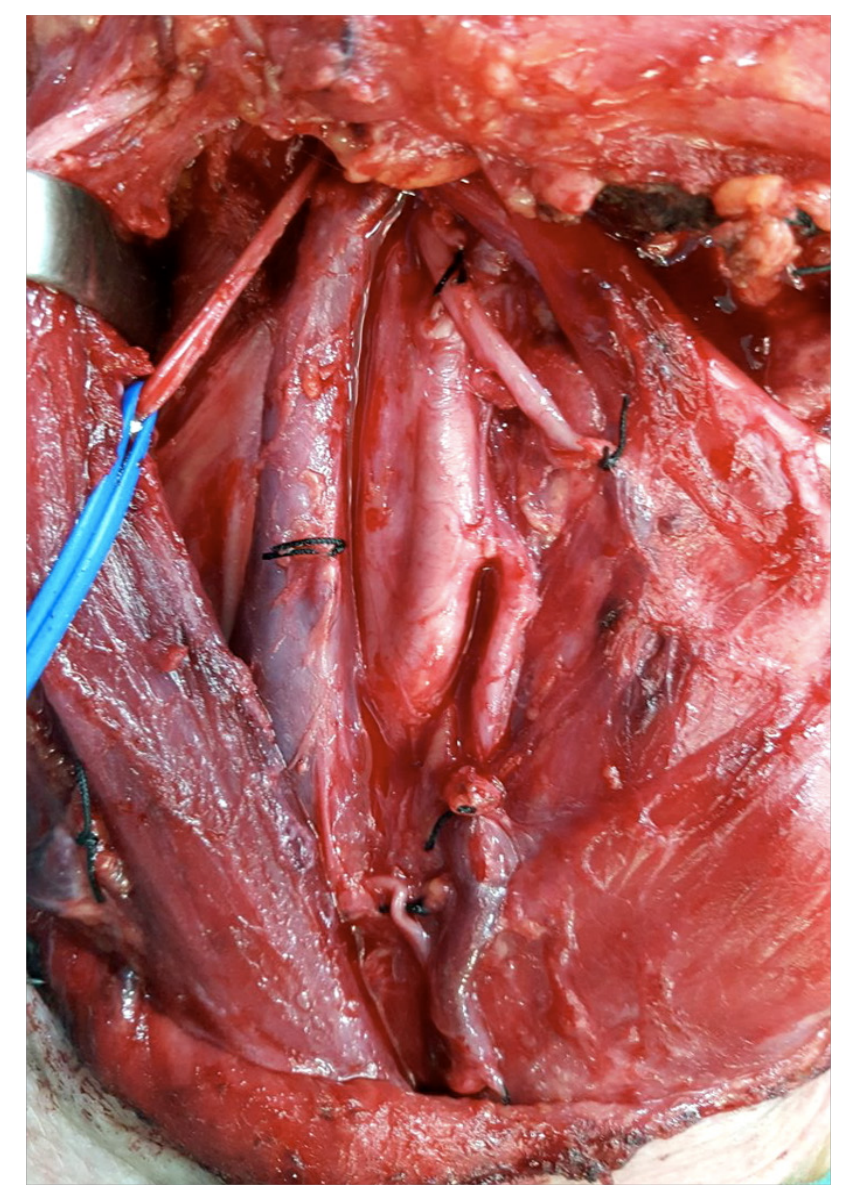

Figure 3: Completed selective supraomohyoid neck dissection, with extirpation of fibro-fatty tissue and lymph neck nodes from levels I to III, while preserving the sternocleidomastoid muscle, accessory spinalis nerve and internal jugular vein

frequently in head and neck cancer patients. ${ }^{[4]}$ Therefore, it is challenging to optimize management of the neck in T1-T2 oral cancer and tailor management in the individual patient.

Several articles have stated that tumor depth is an important factor contributing to neck lymph node metastasis. ${ }^{[72-76]}$ Other factors such as differentiation, DNA aneuploid, T stage, perineural invasion, infiltration pattern, and other molecular markers have also been proposed. ${ }^{[35,77-79]}$ In general, these studies agree that the depth of tumor invasion more than 4 to $5 \mathrm{~mm}$ will have higher risk of neck lymph node metastasis.

Because of the dense lymphatic interconnections of the tongue and FOM, bilateral and contralateral spread is not uncommon in early oral lesions of these anatomic sites. ${ }^{[6,26,33,66]}$ Contralateral regional metastases have been described in some series of early tumors of the oral cavity facing elective ipsilateral neck dissection. ${ }^{[26,66]}$

These results are in accordance with the findings of Cunningham et al $^{[39]}$ in their analysis of cervical metastases in stage I and II squamous cell carcinoma (SCC) of the oral cavity. The possibility of metastatic spread to lower lymphatic levels at the neck (levels IV-V) or the development of the so-called "skip metastases" challenges selective supraomohyoid neck dissection as an effective therapeutic method of regional control in oral cancer patients. ${ }^{[35,69]}$ Byers et al. ${ }^{[69]}$ found a $15.8 \%$ incidence of level IV metastases as the only metastatic manifestation or involvement of level III without compromising of levels I and II in 277 oral tongue cancer patients. Lydiatt et al. ${ }^{[35]}$ concluded that the inclusion of the lower jugular chain with the supraomohyoid neck dissection had increased the effectiveness of regional control by $20 \%$ to $24 \%$.

Shah et al. ${ }^{[68]}$ found a $3.5 \%$ incidence of nodal metastases at levels IV and $\mathrm{V}$ and a $1.5 \%$ incidence of isolated level involvement, outside the supraomohyoid triangle (level I, II, or III) in their review of the patterns of cervical metastases in 192 squamous cell carcinoma of the oral cavity. These findings emphasize the effectiveness of selective supraomohyoid neck dissection when used electively to control cervical micrometastases [Figures 2 and 3].

Many pretreatment imaging techniques to diminish the incidence of occult metastases haven been studied, and comparative studies have shown USgFNAC to be the most accurate. However, the sensitivity is only in the range of $50-65 \%$ and whether imaging should change the current management of the cN0 neck remains controversial. In early OSCC, sentinel node biopsy (SNB) has a sensitivity of 93\% for the detection of occult lymph node metastases. ${ }^{[62 \mid}$ This figure is probably even higher in the more experienced centers. Thus, SNB has a much higher sensitivity and can be used to better select candidates for neck dissection. Although the long-term follow-up results of the large European SENT study are not yet reported, several centers have already adopted sentinel node biopsy as an alternative to END. In the American National Comprehensive Cancer Network (NCCN) guidelines as well as the guidelines of the Dutch Head and Neck Society, sentinel node biopsy is already mentioned as an alternative for END. However, this technique does require experience and is currently recommended only for centers with the necessary facilities and expertise. The group of Tata Memorial Centre recently reported their experience in 51 early OSCC patients and found a sensitivity of only $71 \%$. In spite of this low percentage, they concluded that SNB is a reliable method to detect occult metastases which has potential to replace END. ${ }^{\text {[63] }}$

Sentinel node biopsy has been investigated in many cancer centres. $^{[80]}$ Some authors postulate that SNB might replace END in the treatment of early, node-negative OSCC. ${ }^{[81,82]}$ Other studies, however, do not find such a high sensitivity for SNB, suggesting that this approach should primarily be considered for patients with T1 tumours and a low risk of occult metastases. ${ }^{[83-85]}$ In the future, we believe that SNB will play a vital role in classification for patients with T1 tumours who would benefit from END. Nevertheless, before further prospective studies confirm that SNB can actually replace END for T2 tumours, simultaneous neck dissection is still the most preferred recommended neck management choice for stage II OSCC. ${ }^{[16]}$

In conclusion, a few non-randomized studies have shown no advantages of END when strict USgFNAC follow-up was employed. In these studies, the salvage rates were much higher and relapses were diagnosed earlier. However, it is a highly operator dependent investigation. It also requires additional manpower and time, thus making its routine use difficult in a high volume cancer center. Thus, if routine very strict follow-up using USgFNAC by a well-trained ultrasonographer cannot be assured, 
END is the safest strategy. We emphasize the effectiveness of selective supraomohyoid neck dissection when used electively to control cervical micrometastases.

Therefore, it seems to not be practical to use the depth of tumor invasion or other pathologic parameters as a guideline to determine whether the patient should receive END or not. It will become two stages of surgery. Instead, it is proper to proceed with supraomohyoid neck dissection at the time of neck operation.

The next step in refinement of the choice to manage the $\mathrm{cNO}$ neck with END or observation is to perform a RCT comparing END with close observation in OSCC patients with a cN0 neck based on sentinel node biopsy.

\section{Financial support and sponsorship Nil.}

\section{Conflicts of interest}

There are no conflicts of interest.

\section{REFERENCES}

I. Flach GB, Tenhagen M, De Bree R, Brakenhoff RH,Van der Waal I, Bloemena E, Kuik DJ, Castelijns JA, Leemans CR. Outcome of patients with early stage oral cancer managed by an observation strategy towards the NO neck using ultrasound guided fine needle aspiration cytology. No survival difference as compared to elective neck dissection. Oral Oncol 20I3;49:157-64.

2. Leemans CR, Tiwari R, van der Waal I, Karim AB, Nauta JJ, Snow GB. The efficacy of comprehensive neck dissection with or without postoperative radiotherapy in nodal metastases of squamous cell carcinoma of the upper respiratory and digestive tracts. Laryngoscope 1990;100:1 194-8.

3. Weiss $\mathrm{MH}$, Harrison LB, Isaacs RS. Use of decision analysis in planning a management strategy for the stage N0 neck. Arch Otolaryngol Head Neck Surg 1994; 120:699-702.

4. O'Brien CJ,Traynor SJ, McNeil E, McMahon JD, Chaplin JM.The use of clinical criteria alone in the management of the clinically negative neck among patients with squamous cell carcinoma of the oral cavity and oropharynx. Arch Otolaryngol Head Neck Surg 2000; 126:360-5.

5. Kaya S, Yilmaz T, Gursel B, Sarac S, Sennaroğlu L. The value of elective neck dissection in treatment of cancer of the tongue. Am J Otolaryngol 200I;22:59-64.

6. Dias FL, Kligerman J, Matos de Sá G, Arcuri RA, Freitas E, Farias T, Matos F, Lima RA. Elective neck dissection versus observation in stage I squamous cell carcinomas of the tongue and floor of the mouth. Otolaryngol Head Neck Surg 200I; 125:23-9.

7. Smith GI, O'Brien CJ, Clark J, Shannon KF, Clifford AR, McNeil EB, Gao K. Management of the neck in patients with $\mathrm{TI}$ and $\mathrm{T} 2$ cancer in the mouth. $\mathrm{Br}$ J Oral MaxillofacSurg 2004;42:494-500.

8. Duvvuri U, Simental AA, D'Angelo G, Johnson JT, Ferris RL, Gooding W, Myers EN. Elective neck dissection and survival in patients with squamous cell carcinoma of the oral cavity and oropharynx. Laryngoscope 2004; I | 4:2228-34.

9. Amaral TM, Da Silva Freire AR, Carvalho AL, Pinto CAL, Kowalski LP. Predictive factors of occult metastasis and prognosis of clinical stages I and II squamous cell carcinoma of the tongue and floor of the mouth. Oral Oncol 2004:40:780-6.

10. Keski-Säntti H, Atula T, Törnwall J, Koivunen P, Mäkitie A. Elective neck treatment versus observation in patients with $\mathrm{TI} / \mathrm{T} 2 \mathrm{~N} 0$ squamous cell carcinoma of oral tongue. Oral Oncol 2006;42:96-I0I.

II. Lim YC, Choi EC. Unilateral, clinically T2N0, squamous cell carcinoma of the tongue: surgical outcome analysis. Int J Oral Maxillofac Surg 2007;36:6I 0-4.

12. lype EM, Sebastian P, Mathew A, Balagopal PG, Varghese BT, Thomas S. The role of selective neck dissection (I-III) in the treatment of node negative (N0) neck in oral cancer. Oral Oncol 2008;44: I I34-8.

13. Huang SF, Kang CJ, Lin CY, Fan KH, Yen TC, Wang HM, Chen IH, Liao CT, Cheng AJ, Chang JT. Neck treatment of patients with early stage oral tongue cancer: comparison between observation, supraomohyoid dissection, and extended dissection. Cancer 2008; I 12:1066-75.
14. Yuen AP, Ho CM, Chow TL, Tang LC, Cheung WY, Ng RW,Wei WI, Kong CK, Book KS, Yuen WC, Lam AK, Yuen NW, Trendell-Smith NJ, Chan YW, Wong BY, Li GK, Ho AC, Ho WK, Wong SY,Yao TJ. Prospective randomized study of selective neck dissection versus observation for N0 neck of early tongue carcinoma. Head Neck 2009;31:765-72.

15. D'Cruz AK, Siddachari RC, Walvekar RR, Pantavaidya GH, Chaukar DA, Deshpande MS, Pai PS, Chaturvedi P. Elective neck dissection for the management of the N0 neck in early cancer of the oral tongue: need for a randomized controlled trial. Head Neck 2009;31:618-24.

16. Feng Z, Li JN, Li CZ,Guo CB. Elective neck dissection versus observation in the management of early tongue carcinoma with clinically node-negative neck: a retrospective study of 229 cases. J Craniomaxillofac Surg 2014;42:806-I0.

17. Brugère JM, Mosseri VF, Mamelle G, David JM, Buisset E, Vallicioni J, Raucourt D, Szpirglas HJ, Asselain BJ. Nodal failures in patients with NO $\mathrm{N}^{+}$oral squamous cell carcinoma without capsular rupture. Head Neck 1996; I8: I33-7.

18. Khafif RA, Gelbfish GA, Tepper P, Attie JN. Elective radical neck dissection in epidermoid cancer of the head and neck. A retrospective analysis of 853 cases of mouth, pharynx, and larynx cancer. Cancer 1991;67:67-7I.

19. Okamoto $M$, Nishimine $M$, Kishi M, Kirita T, Sugimura M, Nakamura M, Konishi N. Prediction of delayed neck metastasis in patients with stage I/II squamous cell carcinoma of the tongue. J Oral Pathol Med 2002;31:227-33.

20. De Bree R,Van den Brekel MW. Elective neck dissection versus observation in the clinically node negative neck in early oral cancer: do we have the answer yet? Oral Oncol 2015;5I:963-5.

21. Kowalski LP, Sanabria A. Elective neck dissection in oral carcinoma: a critical review of the evidence. Acta Otorhinolaryngol ltal 2007;27: I I3-7.

22. Vijayakumar M, Burrah R, Sabitha KS, Nadimul H, Rajani BC. To operate or not to operate NO neck in early cancer of the tongue? A prospective study. Indian J Surg Oncol 20II;2:172-5.

23. Teichgraeber JF, Clairmont AA. The incidence of occult metastasis for cancer of the oral tongue and floor of the mouth: treatment rationale. Head Neck Surq 1984;7:15-21.

24. DiTroia JF. Nodal metastases and prognosis in carcinoma of the oral cavity. Otolaryngol Clin North Am 1972;5:333-4I.

25. O'Brien C], Lahr CJ, Soong SJ. Surgical treatment of early-stage carcinoma of the oral tongue--wound adjuvant treatment be beneficial? Head Neck Surg 1986;8:40I-8.

26. Yuen APW, Wei WI, Wong YM. Elective neck dissection versus observation in the treatment of early oral tongue carcinoma. Head Neck 1997; 19:583-8.

27. Spiro RH, Strong EW. Epidermoid carcinoma of the oral cavity and oropharynx. Arch Surg 1973;107:382-4.

28. Spiro RH, Strong EW. Surgical treatment of cancer of the tongue. Surg Clin NAm 1974;54:757-65.

29. Lee JG, Litton WB. Occult regional metastases: carcinoma of the oral tongue. Laryngoscope 1972;82:1273-80.

30. Fu KK, Lichter A, Galante M. Carcinoma of the floor of the mouth: an analysis of treatment results and the sites and causes of failure. Int J Radiat Oncol Biol Phys 1976;1:829-37.

31. Whitehurst JO, Droulias CA. Surgical treatment of squamous cell carcinoma of the oral tongue. Arch Otolaryngol 1977;103:212-5.

32. Johnson JT, Leipzig B, Cummings CW. Management of TI carcinoma of the anterior aspect of the tongue. Arch Otolaryngol 1980;106:249-5I.

33. Ho CM, Lam KH, Wei WI. Occult lymph node metastases in small oral tongue cancers. Head Neck 1992; |4:359-63.

34. Kligerman J, Lima RA, Soares JR, Prado L, Dias FL, Freitas EQ, Olivatto LO. Supraomohyoid neck dissection in the treatment of TI/T2 squamous cell carcinoma of oral cavity. Am J Surg 1994; 168:391-4.

35. Lydiatt DD, Robins KT, Byers RM, Wolf PF. Treatment of stage I and II oral tongue cancer. Head Neck 1993; 15:308-12.

36. Van den Brekel MWM, van der Waal I, MeijerCJ, Freeman JL, Castelijns JA, Snow GB. The incidence of micrometastases in neck dissection specimens obtained from elective neck dissections. Laryngoscope 1996; 106:987-91.

37. Van den Brekel MWM, Castelijns JA, Stel HV, Golding RP, Meyer CJ, Snow GB. Modern imaging techniques and ultrasound-guided aspiration cytology for the assessment of neck node metastases: a prospective comparative study. Eur Arch Otorhinolaryngol 1993;250: I I-7.

38. Snow GB, Patel P, Leemans CR, Tiwari R. Management of cervical lymph nodes in patients with head and neck cancer. Eur Arch Otorhinolaryngol 1992;249: 187-94.

39. Cunningham MJ, Johnson JT, Myers EN, Schramm VL Jr, Thearle PB. Cervical lymph node metastasis after local excision of early squamous cell carcinoma of the oral cavity. Am J Surg 1986; I52:361-66.

40. Beenken SW, Krontiras H, Maddox WA, Peters GE, Soong S, Urist MM.TI and T2 squamous cell carcinoma of the oral tongue: prognostic factors and the role of elective lymph node dissection. Head Neck 1999;2 I:124-30. 
4I. Yii NW, Patel SG, Rhys-Evans PH, Breach NM. Management of the N0 neck in early cancer of the oral tongue. Clin Otolaryngol Allied Sci 1999;24:75-9.

42. Spiro RH, Strong EW. Discontinuous partial glossectomy and radical neck dissection in selected patients with epidermoid carcinoma of the mobile tongue. Am J Surg 1973; I26:544-6.

43. Dijkstra PU, van Wilgen PC, Buijs RP, Brendeke W, de Goede CJ, Kerst A, Koolstra M, Marinus J, Schoppink EM, Stuiver MM, van de Velde CF, Roodenburg JL. Incidence of shoulder pain after neck dissection: a clinical explorative study for risk factors. Head Neck 200 1;23:947-53.

44. El Ghani F, van den Brekel MW, de Goede CJT, Kuik DJ, Leemans CR, Smeele LE. Shoulder function and patient well-being after various types of neck dissections. Clin Otolaryngol Allied Sci 2002;27:403-8.

45. Inoue H, Nibu KI, Saito M, Otsuki N, Ishida H, Onitsuka T, Fujii T, Kawabata K, Saikawa M. Quality of life after neck dissection. Arch Otolaryngol Head Neck Surg 2006;132:662-6.

46. Stuiver MM, van Wilgen CP, de Boer EM, de Goede CJ, Koolstra M, van Opzeeland A, Venema P, Sterken MW, Vincent A, Dijkstra PU. Impact of shoulder complaints after neck dissection on shoulder disability and quality of life. Otolaryngol Head Neck Surg 2008; I39:32-9.

47. Braakhuis BJ,Tabor MP, Leemans CR, van derWaal I,Snow GB, Brakenhoff RH Second primary tumors and field cancerization in oral and oropharyngeal cancer: molecular techniques provide new insights and definitions. Head Neck 2002;24:198-206

48. Smith GI, O'Brien CJ, Clark J, Shannon KF, Clifford AR, McNeil EB, Gao K. Management of the neck in patients with TI and T2 cancer in the mouth. $\mathrm{Br}$ J Oral Maxillofac Surg 2004;42:494-500.

49. Duvvuri U, Simental AA, D’Angelo G, Johnson JT, Ferris RL, Gooding W, Myers EN. Elective neck dissection and survival in patients with squamous cell carcinoma of the oral cavity and oropharynx. Laryngoscope 2004; I |4:2228-34

50. lype EM, Sebastian P, Mathew A, Balagopal PG, Varghese BT, Thomas S. The role of selective neck dissection (I-III) in the treatment of node negative (N0) neck in oral cancer. Oral Oncol 2008;44: I I34-8.

5I. Capote A, Escorial V, Munoz-Guerra MF, Rodriguez-Campo FJ, Gamallo C Naval L. Elective neck dissection in early-stage oral squamous cell carcinoma - does it influence recurrence and survival? Head Neck 2007;29:3-II.

52. Fasunla AJ, Greene BH, Timmesfeld N, Wiegand S, Werner JA, Sesterhenn AM. A meta-analysis of the randomized controlled trials on elective neck dissection versus therapeutic neck dissection in oral cavity cancers with clinically node-negative neck. Oral Oncol 20I I;47:320-4.

53. D'Cruz AK, Dandekar MR. Elective versus therapeutic neck dissection in the clinically node negative neck in early oral cavity cancers: do we have the answer yet? Oral Oncol 20I I;47:780-2.

54. D'Cruz AK, Vaish R, Kapre N. Elective versus therapeutic neck dissection in node-negative oral cancer. N Engl J Med 20I5;373:52I-9.

55. Ganly I, Patel S, Shah J. Early stage squamous cell cancer of the oral tongueclinicopathologic features affecting outcome. Cancer 20 I 2; I 8: I0 I-I I.

56. Tsang RK, Chung JC, Howe To VS, Chan JY, Ho WK, Wei WI. Efficacy of salvage neck dissection for isolated nodal recurrences in early carcinoma of oral tongue with watchful waiting management of initial N0 neck. Head Neck 201।;33:|482-5.

57. Borgemeester MC, van den Brekel MW, van Tinteren H. Ultrasound-guided aspiration cytology for the assessment of the clinically NO neck: factors influencing its accuracy. Head Neck 2008;30:1505-13.

58. Van den Brekel MW, Castelijns JA, Snow GB. The size of lymph nodes in the neck on sonograms as a radiologic criterion for metastasis: how reliable is it? AJNR Am J Neuroradiol 1998; 19:695-700.

59. Van den Brekel MW, Reitsma LC, Quak JJ. Sonographically guided aspiration cytology of neck nodes for selection of treatment and follow-up in patients with N0 head and neck cancer. AJNR Am J Neuroradiol 1999;20:I727-3I.

60. Wensing BM, Merkx MA, de Wilde PC, Marres HA, van den Hoogen FJ. Assessment of preoperative ultrasonography of the neck and elective neck dissection in patients with oral squamous cell carcinoma. Oral Oncol 2010;46:87-91.

6I. Nieuwenhuis EJ,Castelijns JA, Pijpers R, van den Brekel MW, Brakenhoff RH, van der Waal I, Snow GB, Leemans CR. Wait-and-see policy for the NO neck in early-stage oral and oropharyngeal squamous cell carcinoma using ultrasonography-guided cytology: is there a role for identification of the sentinel node? Head Neck 2002;24:282-9.

62. Govers TM, Hannink G, Merkx MA, Takes RP, Rovers MM. Sentinel node biopsy for squamous cell carcinoma of the oral cavity and oropharynx: a diagnostic meta-analysis. Oral Oncol 2013;49:726-32.

63. Chaturvedi P, Datta S, Arya S. Prospective study of ultrasound-guided fine-needle aspiration cytology and sentinel node biopsy in the staging of clinically negative TI and T2 oral cancer. Head Neck 20I 5;37: I 504-8.

64. Andersen PE, Cambronero E, Shaha AR, Shah JP. The extent of neck disease after regional failure during observation of the No neck. Am J Surg 1996; |72:689-9|.

65. Fakih AR, Rao RS, Patel AR. Prophylactic neck dissection in squamous cell carcinoma of oral tongue: a prospective randomized study. Semin Surg Oncol 1989;5:327-30

66. Kowalski LP, Medina JE. Nodal metastases: predictive factors. Otolaryngol Clin North Am 1998;31:62 1-37.

67. Ossoff RH, Sisson GA. Lymphatics of the floor of the mouth and neck: anatomical studies related to contralateral drainage pathways. Laryngoscope 1981;91:1847-50.

68. Shah JP, Candela FC, Poddar AK. The patterns of cervical lymph node metastases from squamous carcinoma of the oral cavity. Cancer 1990;66:109-13.

69. Byers RM, Weber RS, Andrews T, McGill D, Kare R, Wolf P. Frequency and therapeutic implications of "skip metastases" in the neck from squamous carcinoma of the oral tongue. Head Neck 1997; 19:14-9.

70. Kowalski LP, Bagietto R, Lara JR, Santos RL, Silva JF Jr, Magrin J. Prognostic significance of the distribution of neck node metastasis from oral carcinoma. Head Neck 2000;22:207-I4.

7I. Woolgar JA. Histological distribution of cervical lymph node metastases from intraoral/oropharyngeal squamous cell carcinomas. Br J Oral Maxillofac Surg 1999;37:175-80

72. Byers RM, El Naggar AK, Lee YY, Rao B, Fornage B, Terry NH, Sample D, Hankins P, Smith TL, Wolf PJ. Can we detect or predict the presence of occult nodal metastases in patients with squamous carcinoma of the oral tongue? Head Neck 1998;20: I38-44

73. Fukano H, Matsuura H, Hasegawa $\mathrm{Y}$, Nakamura S. Depth of invasion as a predictive factor for cervical lymph node metastasis in tongue carcinoma. Head Neck 1997; 19:205-10.

74. Lim SC, Zhang S, Ishii G, Endoh Y, Kodama K, Miyamoto S, Hayashi R, Ebihara S, Cho JS, Ochiai A. Predictive markers for late cervical metastasis in stage I and II invasive squamous cell carcinoma of the oral tongue. Clin Cancer Res 2004;10:166-72

75. Asakage T,Yokose T, Mukai K, Tsugane S,Tsubono Y,Asai M, Ebihara S.Tumor thickness predicts cervical metastasis in patients with stage I/II carcinoma of the tongue. Cancer 1998;82:I443-8.

76. Kane SV, Gupta M, Kakade AC, D' Cruz A. Depth of invasion is the most significant histological predictor of subclinical cervical lymph node metastasis in early squamous carcinomas of the oral cavity. Eur J Surg Oncol 2006;32:795-803.

77. Sparano A, Weinstein G, Chalian A, Yodul M, Weber R. Multivariate predictors of occult neck metastasis in early oral tongue cancer. Otolaryngol Head Neck Surg 2004;131:472-6.

78. Spiro RH, Huvos AG, Wong GY, Spiro JD, Gnecco CA, Strong EW. Predictive value of tumor thickness in squamous carcinoma confined to the tongue and floor of the mouth. Am J Surg 1986;152:345-50.

79. Hiratsuka H, Miyakawa A, Nakamori K, Kido Y, Sunakawa H, Kohama G. Multivariate analysis of occult lymph node metastasis as a prognostic indicator for patients with squamous cell carcinoma of the oral cavity. Cancer 1997;80:35I-6.

80. O'Connor R, Pezier T, Schilling C, McGurk M. The relative cost of sentinel lymph node biopsy in early oral cancer. J Craniomaxillofac Surg 20|3;4|:72|-7.

8I. Alkureishi LW, Burak Z, Alvarez JA, Ballinger J, Bilde A, Britten AJ, Calabrese L, Chiesa C, Chiti A, de Bree R, Gray HW, Hunter K, Kovacs AF, Lassmann M, Leemans CR, Mamelle G, McGurk M, Mortensen J, Poli T, Shoaib T, Sloan P, Sorensen JA, Stoeckli SJ, Thomsen JB, Trifiro G,Werner J, Ross GL; European Association of Nuclear Medicine Oncology Committee, European Sentinel Node Biopsy Trial Committee. Joint practice guidelines for radionuclide lymphoscintigraphy for sentinel node localization in oral/oropharyngeal squamous cell carcinoma. Ann Surg Oncol 2009:16:3190-210.

82. Stoeckli SJ, Alkureishi LW, Ross GL. Sentinel node biopsy for early ora and oropharyngeal squamous cell carcinoma. Eur Arch Otorhinolaryngol 2009;266:787-93.

83. Keski-Säntti H, Kontio R, Leivo I, Törnwall J, Mätzke S, Mäkitie AA, Atula T. Sentinel lymph node biopsy as an alternative to wait and see policy in patients with small TI oral cavity squamous cell carcinoma. Acta Otolaryngol 2008; I 28:98-102.

84. Keski-Säntti H, Kontio R, Törnwall J, Leivo I, Mätzke S, Suominen S, Leppänen E,Atula T. Sentinel lymph node biopsy or elective neck dissection for patients with oral squamous cell carcinoma? Eur Arch Otorhinolaryngol 2008;265:SI3-7

85. Thiele OC, Seeberger R, Flechtenmacher C, Hofele C, Freier K. The role of elective supraomohyoidal neck dissection in the treatment of early, node-negative oral squamous cell carcinoma (OSCC): a retrospective analysis of 122 cases. Craniomaxillofac Surg 2012;40:67-70. 